\title{
Localised Prostate Versus Whole Pelvic Irradiation in High Risk Prostate Cancer, Single Institute Experience
}

\author{
Rasha Mohamed Abdel Latif*, Ghada Ezzat Eladawei \\ Clinical Oncology and Nuclear Medicine Department, Faculty of Medicine, Mansoura University, Mansoura, Egypt \\ Email address: \\ rosha20075@yahoo.com (R. M. A. Latif), ghadaeladawy@hot mail.com (G. E. Eladawei) \\ ${ }^{*}$ Corresponding author \\ To cite this article: \\ Rasha Mohamed Abdel Latif, Ghada Ezzat Eladawei. Localised Prostate Versus Whole Pelvic Irradiation in High Risk Prostate Cancer, \\ Single Institute Experience. Cancer Research Journal. Vol. 7, No. 1, 2019, pp. 18-24. doi: 10.11648/j.crj.20190701.13
}

Received: January 30, 2019; Accepted: March 12, 2019; Published: April 1, 2019

\begin{abstract}
Objectives: Whole pelvic irradiation [WPRT] versus prostate only radiation [PO-RT] in node negative high risk disease is controversial. This study aims to assess survival benefit of PO-RT against WPRT in high risk negative nodes prostate cancer. Patients and Methods: Patients with high risk prostate cancer and negative pelvic lymph nodes treated randomly either with WPRT [arm1] or PORT [arm2] from June-2014-June-2017. Eligible patients were $>18$ years, risk factors selected are $\geq \mathrm{T} 3$, GS $\geq 8$, or PSA $\geq 20 \mathrm{nglml}$. All patients received hormonal therapy as neo-adjuvant and concurrent with radiation and followed to 2-3 years. Univariate and multivariate analysis are performed. The primary end point was progression free survival [PFS], and the secondary was OAS and toxicity assessment. Results: Ninety four patients included, 48 received WPRT arm and 46 received PORT. With median follow up 26 months there was no significant difference in PFS, or OAS [P=0.994 and $0.505]$ respectively between both arms. On univariate analysis PFS was significantly better in lower stage [P=0.014], lower GS $[\mathrm{P}=0.000]$, lower number of risk factors $[\mathrm{P}=0.016]$. Only 2 cases with late grade 3 gastrointestinal toxicity in observed in WPRT $[\mathrm{P}=0.044]$, and one case late grade 3 genitourinary in PORT with no significance $[\mathrm{P}=0.096]$. Conclusion: Addition of pelvic irradiation in high risk node negative prostate cancer has no impact on survival in comparison to PORT.
\end{abstract}

Keywords: Prostate Cancer, Nodal Irradiation, Pelvic Radiation, High Risk

\section{Introduction}

Prostate cancer represents $4.5 \%$ of cancer in Egyptian males [1-2]. In the United States about 220,000 men diagnosed yearly with prostate cancer [3].

About $15 \%$ of prostate cancer represented as high risk disease [4], and it is considered aggressive form which consequently associated with distant metastases and mortality.

Defining risk factors of prostate cancer was limited by depending on TNM staging only but now pre-treatment PSA level and Gleason score together with clinical stage are predictors of prostate cancer-specific survival outcomes which in turn developed many definitions of high risk prostate cancer [5-7].

It is well understood that local control of the disease decrease incidence of distant metastases and cancer specific mortality [8-9]. Consequently, many studies had shown that combination of external beam radiation and androgen deprivation therapy (ADT) improved 10 years overall survival (OAS) and 10 years prostate cancer specific survival in high risk prostate cancer in comparison to each modality alone [10-13].

There are trials which proved that PFS improved in patients with risk of nodal involvement $>15 \%$ according to Roch formula [14] when received whole pelvic irradiation as elective compared with prostate only radiotherapy [15-17]. This was attributed to the concept of presence of nodal micro-metastasis which not apparent in clinically localised high- risk prostate cancer [14].

Although, of this benefit in PFS, whole pelvic radiotherapy (WPRT) associated with increased gastrointestinal toxicity $[15,18]$, as well as hematologic toxicity especially in extended field to include common iliac lymph node [19-21].

In addition to toxicity, there was nodal recurrence reported after WPRT [22-23], these reasons motivated researchers to compare WPRT to PO-RT and there were trials which failed to confirm the clinical benefit as regard PFS and OAS both [22-24].

In this study try to assess the PFS and OAS in patients 
received PO- RT, versus WPRT in high risk prostate cancer with -ve lymph node involvement and assess toxicity.

\section{Patients and Methods}

This is a prospective phase II study done in Clinical Oncology \& Nuclear Medicine department, Mansoura University, in the period June 2014 to June 2017.

\subsection{Inclusion Criteria}

Patients included in the study full filled the following criteria:

Pathologically proved prostate cancer, $\geq 18$ years old, with high risk factors defined according to National Cancer Comprehensive Network guidelines [25] as clinical stage $\geq$ T3, Gleason Score (GS) $\geq 8$, or prostate specific antigen (PSA) $\geq 20$ ng. Patients included confirmed radiologically to be negative nodal or metastatic involvement.

Patients excluded if they:

Have +ve lymph nodes or metastases.

Underwent lymphadenectomy.

Received previous chemotherapy or pelvic irradiation for any cause.

Informed consent from the patient has taken.

\subsection{Pretreatment Evaluation}

Before treatment, a complete history and physical examination are undertaken, and recent imaging either computed tomography (CT) scans or MRI were performed and bone scan for staging. Pre-treatment GS and PSA should be performed.

\subsection{Treatment Plan}

The Roach equation was used to calculate percentage risk of lymph node involvement [14]. Patients randomly classified into two arms, 1st received prostate and whole pelvic radiotherapy (WPRT) formed of 48 patients and 2nd arm received prostate only radiotherapy (PO-RT) which formed of 46 patients. All patients received ADT 2-3 years. Patients who don't continue the arm for any cause excluded from the study.

\subsubsection{Radiotherapy Technique}

Prostate and pelvis radiotherapy included all or most of pelvis with additional boost to prostate, while PO-RT included prostate only with or without seminal vesicles (S.V.).

Patient prepared with full bladder and empty rectum, placed in supine position with arms folded over chest, patient immobilized in comfortable and reproducible position. For 3D technique CT scan performed from midabdomen to mid femur with slice thickness $5 \mathrm{~mm}$.

As regard CTV in case of WPRT included prostate was $7 \mathrm{~mm}$ around internal, external, presacral, hypogastric, and obturator LN. In case of prostate only CTV included prostate and base of seminal vesicles, or whole seminal vesicles if infilterated. Planning target volume [PTV] included CTV with $1 \mathrm{cmm}$ in all directions except around prostate posteriorly $6 \mathrm{~mm}$ to limit dose to rectum. Radiotherapy performed with using multileaf collimator.

For prostate and seminal vesicles used 3-dimensional conformal radiotherapy (3-DCR) with $1 \mathrm{~cm}$ extension in all dimension, for clinical target volume using multileaf collimators (MLC). As regard the dose, patients treated with PO-RT received dose $>66 \mathrm{~Gy}$, in 1.8-2 Gy/fraction for prostate and base of SV or whole SV, if divided into 2 phases phase I prostate and base of SV or whole SV 56GY, and phase II to prostate only $>66 \mathrm{~Gy}$. Those received LN irradiation, EBRT delivered with dose 46.8 Gy in $1.8 \mathrm{~Gy} /$ fraction for $\mathrm{LN}$, prostate, and base of seminal vesicles, and boost to prostate and base of $\mathrm{SV}$ to total dose $>66 \mathrm{~Gy}$ in 1.8 /fraction.

Organ at risk delineated included small bowel, rectum, bladder, and both femoral heads.

\subsubsection{The Hormonal Therapy}

consisted of luteinizing hormone releasing hormone analogue (LHRHa) and anti-androgen starting 2 months before radiation and continue with and after for 2-3 years.

The primary end point was PFS rate including local, nodal, or distant metastases. And 2ry end points were OAS and assessment of treatment toxicity.

\subsection{Toxicity Assessment}

Adverse events were graded according to NCI-CTC version 3.

\subsection{Follow Up}

Follow-up examinations and response assessment included clinically by DRE, biologically by PSA, and radiologically by MRI or CT obtained 2, 6 months after completion of treatment and then every 3-6 months until progression or death. CT or MRI and bone scan were mandatory on PSA progression or when symptoms were suspicious for tumour progression.

\subsection{Statistical Analysis}

Analysis performed using SPSS version 20. The PFD defined from time of study designed till disease progression, death, or lost follow up. Overall survival calculated from date of diagnosis to date of death.

Qualitative data was presented as number and percent, Chi-square test was used for comparison between groups. Non-parametric data was presented as min - max and median. Mann-Whitney test and Kruskal-Wallis test were used for comparison between groups.

Survival calculated using Kaplan-Meier method, with using Long-rank test to compare survival and other variables between two arms. A multivariate analysis was tested by a Cox proportional hazards model. P-value less than 0.05 were considered statistically significant. Median follow-up time was calculated using a reverse Kaplan-Meier estimate. Same tests used for 2ry end point, the OAS. Statistical analysis was performed using SPPS version 20. 


\section{Results}

\subsection{Patients' Characteristics}

This is a prospective study included 94patients with high risk prostate adenocarcinoma. The study included two arms, arm 1 received WPRT included $48(51.1 \%)$ patients and arm 2 received PORT was 46 patients (48.9\%). Median age of all was 67years, ranged from 53-79 years with $59.6 \%$ in age group $>65$ years. Performance status 1 was the most one as presented in 62 patients $(66 \%)$.

Stages T2, T3, a T4 were diagnosed in patients in 26.6, 48.9 , and $24.5 \%$ respectively. Well differentiated grade was the least grade $(3.2 \%)$, while moderate one was the most one (73.4\%). Prostate specific antigen (PSA) was categorized into 3 groups $\leq 10,10-20$, and $\geq 20 \mathrm{ng}$, and results showed that PSA was $\geq 20$ in $62.8 \%$ of patients. Gleason score 7 and 8 were in $38.3 \%$ an $37.2 \%$ respectively.

Median follow up time was 26 months with range 3-48 months in all patients. There were $64.9 \%$ of patients with $>1$ risk factor ( 2 and 3 risk factors). Patients' characteristics are listed in table 1 . The patients who received WPRT were younger age $(\mathrm{P}=$ $0.019)$, higher $\mathrm{T}$ stage $(\mathrm{P}=0.021)$, better $\mathrm{PS}(\mathrm{P}=0.000)$, lower number of risk factors $(\mathrm{P}=0.001)$ than those in PORT. On the other hand there were comparable results between both groups in PSA $(\mathrm{P}=0.315), \mathrm{GS}(\mathrm{P}=0.477)$, in grades $(\mathrm{P}=0.784)$, and in total given dose of radiation $(\mathrm{P}=0.915)$.

\subsection{Survival}

The 2 years PFS was $81 \%$ (figure 1), 2 years OAS was $94 \%$ (figure 2). The 2 years PFS was and $78 \%$ in arml versus $81 \%$ arm 2 respectively. As regard 2 years OAS between WPRT versus PORT was $90 \%$ versus $92 \%$ respectively. The median PFS was 26 and 25 in PORT vs WPRT with no significant difference $(\mathrm{P}=0.994)$, and median OAS was 30 and 31 months respectively also with no significance $(\mathrm{P}=0.505)$ between both arms.

Factors affected progression free survival in all patients were analysed, and factors associated with better PFS were GS $(\mathrm{P}=0.000)$, tumor stage $(\mathrm{P}=0.014)$, number of total risk factors $(\mathrm{P}=0.016)$, on the other side the following factors showed no effect on PFS, age $(\mathrm{P}=0.118)$, $\mathrm{PS}(\mathrm{P}=0.055)$, PSA $(\mathrm{P}=0.435)$, grade $(\mathrm{P}=0.570)$, dose of RTH $(\mathrm{P}=0.121)$, although of non-significance with later factors but it was higher in younger age, PS 0 and 1, dose $>70$ Gy. (Table 2)

As regard OAS, no one of the factors showed significance except grade $(\mathrm{P}=0.047)$, however was higher in younger age, lower GS, PS 0, PSA $\leq 10$ (Table 3). A total of 27 patients died 10 in the WPRT arm and 17 in PORT, with no significance difference $(\mathrm{P}=084]$.

According to multivariate, prognostic factors associated with higher PFS were lower stage (95\% CI, 0.134 to 0.684 ) $(\mathrm{P}=0.004)$, and lower GS (95\% CI, 0.013 to 0.266$)(\mathrm{P}=0.000)$. As regard OAS no factors apart from grade showed significance so no MVA performed. Thirty six patients developed recurrence, the main pattern of recurrence was biological in $27.6 \%$ patients and followed by local progression in $14.8 \%$ patients and noticed that $\mathrm{LN}$ recurrence was the least $2.1 \%$ patients, with no significant differences between both arms $(\mathrm{P}=0.123)$.

\subsection{Toxicity}

There were no grade 4 toxicity reported, and grade 3 late toxicity observed in 3 cases as 2 late gastrointestinal in WPRT, and 1 late genitourinary in prostate. There was increase in gastrointestinal toxicity in WPRT especially late and showed significant difference $(\mathrm{P}=0.044)$, while there was no significance in acute nor late genitourinary toxicity between both $(\mathrm{P}=0.096)$, however late toxicity was more common in PORT than WPRT (19.6\% vs 6.3\%). (Table 4$)$.

Table 1. Patients' characteristics.

\begin{tabular}{|c|c|c|c|c|c|c|c|}
\hline \multicolumn{3}{|c|}{ Characteristics all NO \% } & \multicolumn{2}{|c|}{ WPRT NO \% } & \multicolumn{2}{|c|}{ PORT NO \% } & \multirow[t]{2}{*}{$\mathbf{P}$} \\
\hline \multicolumn{7}{|l|}{ Age } & \\
\hline$\leq 65$ & 38 & 40.4 & 25 & 52.1 & 13 & 28.3 & \multirow[t]{2}{*}{0.019} \\
\hline$>65$ & 56 & 59.6 & 23 & 47.9 & 33 & 71.7 & \\
\hline \multicolumn{7}{|l|}{ PS } & \multirow{4}{*}{0.000} \\
\hline 0 & 20 & 21.2 & 16 & 33.3 & 4 & 8.7 & \\
\hline 1 & 62 & 66 & 21 & 43.8 & 41 & 89.1 & \\
\hline 2 & 12 & 12.8 & 11 & 22.9 & 1 & 2.2 & \\
\hline \multicolumn{7}{|l|}{ T stage } & \multirow{4}{*}{0.021} \\
\hline $\mathrm{T} 2$ & 25 & 26.6 & 7 & 14.6 & 18 & 39.1 & \\
\hline $\mathrm{T} 3$ & 46 & 48.9 & 26 & 54.2 & 21 & 43.5 & \\
\hline $\mathrm{T} 4$ & 23 & 24.5 & 15 & 31.3 & 8 & 17.4 & \\
\hline \multicolumn{7}{|l|}{ GS } & \multirow{5}{*}{0.477} \\
\hline 6 & 11 & 1.7 & 8 & 16.7 & 3 & 6.5 & \\
\hline 7 & 36 & 38.3 & 18 & 37.5 & 18 & 39.1 & \\
\hline 8 & 35 & 37.2 & 16 & 33.3 & 19 & 41.3 & \\
\hline 9 & 12 & 12.8 & 6 & 12.5 & 6 & 12.5 & \\
\hline \multicolumn{7}{|l|}{ PSA } & \multirow{4}{*}{0.315} \\
\hline$\leq 10$ & 8 & 8.5 & 6 & 12.5 & 2 & 4.3 & \\
\hline $10-20$ & 27 & 28.7 & 12 & 25 & 15 & 32.6 & \\
\hline$\geq 20$ & 59 & 62.8 & 30 & 62.5 & 29 & 63 & \\
\hline \multicolumn{7}{|l|}{ Grade } & \multirow{4}{*}{0.784} \\
\hline Well & 3 & 3.2 & 2 & 4.2 & 1 & 2.2 & \\
\hline Mod. & 69 & 73.4 & 34 & 70.8 & 35 & 76.1 & \\
\hline Poor. & 22 & 23.4 & 12 & 25 & 10 & 21.7 & \\
\hline \multicolumn{7}{|c|}{ No of risks } & \multirow{4}{*}{0.001} \\
\hline 1 & 33 & 35.1 & 19 & 39.6 & 14 & 30.4 & \\
\hline 2 & 41 & 43.6 & 13 & 27.1 & 28 & 60.9 & \\
\hline 3 & 20 & 21.3 & 16 & 33.3 & 4 & 8.7 & \\
\hline \multicolumn{7}{|l|}{ Dose } & \multirow{3}{*}{0.915} \\
\hline$<70$ Gy & 20 & 21.3 & 10 & 20.8 & 10 & 21.7 & \\
\hline$\geq 70 \mathrm{~Gy}$ & 74 & 78.7 & 38 & 79.2 & 36 & 78.3 & \\
\hline
\end{tabular}

Table 2. Prognostic factors predicting PFS.

\begin{tabular}{lll}
\hline Prognostic factors & median PFS & P \\
\hline Age & & \\
$\leq 65$ & 27.5 & 0.118 \\
$>65$ & 24 & \\
PS & & \\
0 & 26 & 0.055 \\
1 & 26 & \\
2 & 15 & \\
T stage & & \\
T2 & 29 & 0.014 \\
T3 & 26 & \\
T4 & 24 & \\
GS & & \\
6 & 35 & 0.000 \\
7 & 26 & \\
8 & 24 & \\
\hline
\end{tabular}




\begin{tabular}{lll}
\hline Prognostic factors & median PFS & P \\
\hline 9 & 14.5 & \\
PSA & & \\
$\leq 10$ & 26 & 0.435 \\
$10-20$ & 23 & \\
$\geq 20$ & 21 & \\
Grade & & \\
Well & 29 & 0.570 \\
Mod. & 26 & \\
Poor & 23 & \\
No of risks & & \\
1 & 29 & 0.016 \\
2 & 24 & \\
3 & 23 & \\
Arm & & 0.994 \\
WPRT & 25.5 & \\
PORT & 26 & \\
Dose or RTH & & 0.121 \\
$<70$ Gy & 23 & \\
$\geq 70$ Gy & 26 & \\
\hline
\end{tabular}

\begin{tabular}{llllll}
\hline Toxicity and grade & $\begin{array}{l}\text { WPRTT [n=48] } \\
\text { NO \% }\end{array}$ & $\begin{array}{l}\text { PORT [n=46] } \\
\text { NO \% }\end{array}$ & P \\
\hline 3 & 1 & 2.1 & 1 & 2.2 & \\
Late: & & & & & \\
0 & 45 & 93.7 & 37 & 80.4 & \\
1 & 2 & 4.2 & 5 & 10.9 & \\
2 & 1 & 2.1 & 3 & 6.5 & \\
3 & 0 & 0 & 1 & 2.2 & \\
Gastrointestinal & & & & & \\
Acute & & & & & \\
0 & 41 & 85.4 & 40 & 87 & \\
1 & 4 & 8.3 & 3 & 6.5 & \\
2 & 2 & 4.2 & 2 & 4.3 & \\
3 & 1 & 2.1 & 1 & 2.2 & 0.044 \\
Late & & & & & \\
0 & 42 & & & 100 & \\
& & 87.5 & 46 & & \\
1 & 2 & 4.2 & 0 & 0 & \\
2 & 2 & 4.2 & 0 & 0 & \\
3 & 2 & 4.2 & 0 & 0 & \\
\hline
\end{tabular}

Table 3. Prognostic factors predicting $O A S$.

\begin{tabular}{|c|c|c|}
\hline Prognostic factors & median OAS & $\mathbf{P}$ \\
\hline \multicolumn{3}{|l|}{ Age } \\
\hline$\leq 65$ & 33 & \multirow[t]{3}{*}{0.109} \\
\hline$>65$ & 30 & \\
\hline \multicolumn{2}{|l|}{ PS } & \\
\hline 0 & 34 & \multirow{3}{*}{0.394} \\
\hline 1 & 32 & \\
\hline 2 & 30 & \\
\hline \multicolumn{3}{|l|}{ T stage } \\
\hline T2 & 32 & \multirow{3}{*}{0.499} \\
\hline T3 & 31 & \\
\hline $\mathrm{T} 4$ & 31 & \\
\hline \multicolumn{3}{|l|}{ GS } \\
\hline 6 & 38 & \multirow{4}{*}{0.104} \\
\hline 7 & 31 & \\
\hline 8 & 33 & \\
\hline 9 & 30 & \\
\hline \multicolumn{3}{|l|}{ PSA } \\
\hline$\leq 10$ & 33 & \multirow{3}{*}{0.260} \\
\hline $10-20$ & 30 & \\
\hline$>20$ & 24.5 & \\
\hline \multicolumn{3}{|l|}{ Grade } \\
\hline Well & 33 & \multirow{3}{*}{$0.047^{*}$} \\
\hline Mod. & 31 & \\
\hline Poor. & 30 & \\
\hline \multicolumn{3}{|l|}{ No of risks } \\
\hline 1 & 31 & \multirow{3}{*}{0.528} \\
\hline 2 & 31 & \\
\hline 3 & 30 & \\
\hline \multicolumn{3}{|l|}{ Arm } \\
\hline WPRT & 31.5 & \multirow[t]{2}{*}{0.994} \\
\hline PORT & 30 & \\
\hline \multicolumn{3}{|l|}{ Dose or RTH } \\
\hline$<70$ Gy & 36 & 0.098 \\
\hline$\geq 70$ Gy & 31 & \\
\hline
\end{tabular}

Table 4. Toxicity profile in both arms.

\begin{tabular}{llllll}
\hline Toxicity and grade & $\begin{array}{l}\text { WPRTT [n=48] } \\
\text { NO \% }\end{array}$ & $\begin{array}{l}\text { PORT [n=46] } \\
\text { NO \% }\end{array}$ & P \\
\hline Genitourinary & & & & & \\
Acute: & 32 & 66.7 & 32 & 69.5 & 0.096 \\
0 & 10 & 20.8 & 8 & 17.4 & \\
1 & 5 & 10.4 & 5 & 10.9 & \\
2 & & &
\end{tabular}

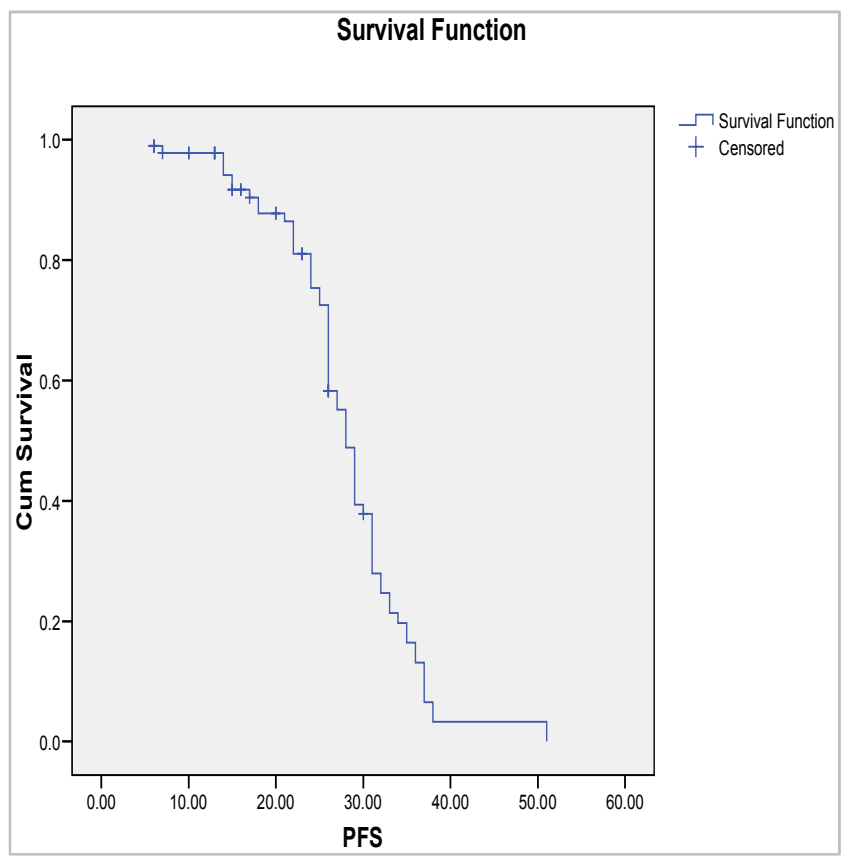

Figure 1. Progression free survival.

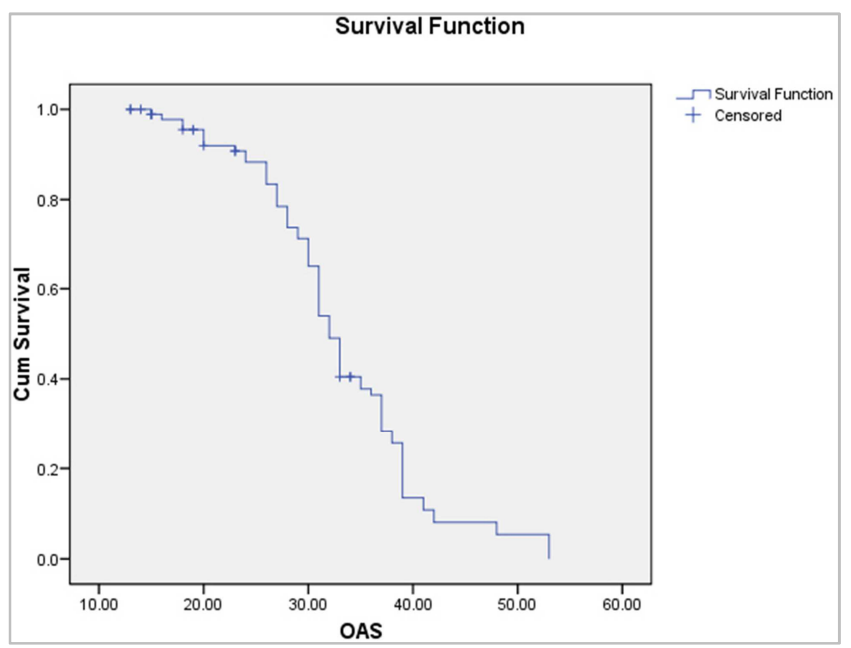

Figure 2. Overall survival. 


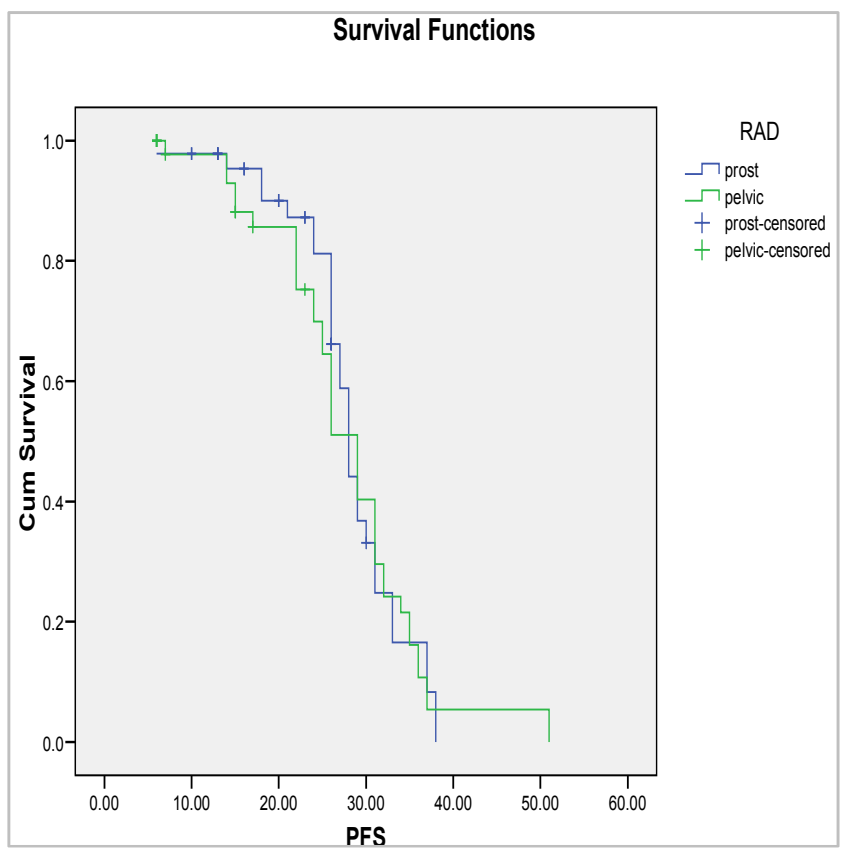

Figure 3. Progression free survival [PFS] in WPRT versus PORT.

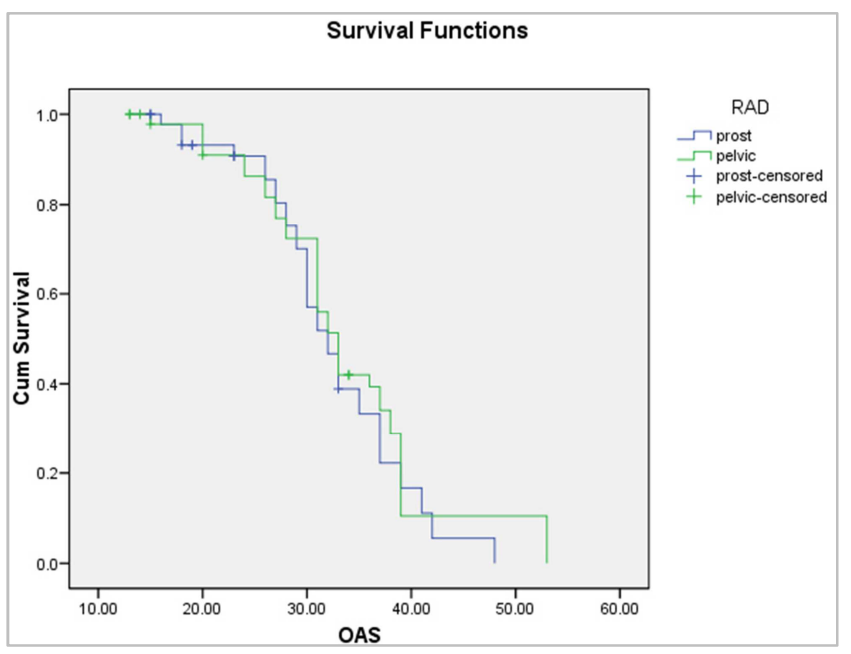

Figure 4. Overall survival [OAS] in WPRT vs PORT.

\section{Discussion}

This prospective study performed on high risk prostate cancer with negative pelvic lymph nodes showed no significant difference in PFS and OAS between both received WPRT and PORT $(\mathrm{P}=0.994 \& 0.505)$ with median follow up 26 months.

High risk prostate cancer associated with higher rate of morbidity and mortality [26], so studies performed to define standard treatment of those groups and they considered that radiotherapy with concurrent hormonal therapy is the standard treatment [27-30]. The researchers tried to detect the benefit of elective pelvic irradiation in high risk prostate cancer with negative lymph nodes.

Whole pelvic radiotherapy (WPRT) associated with improved 5-years biochemical freedom versus PORT [31]. RTOG 7706 was the 1 st trial found no survival improvement observed in patients randomly received WPRT comparing to PORT [32-33].

Later on there were two big trials who studied effect of elective nodal irradiation, the first was RTOG9413 [16], which reported with median follow up of 59.5 months 4 years PFS was improved by $10 \%$ in favour of WPRT, with better results in patients treated with neoadjuvant and concurrent hormonal therapy. An updating of this trial done and confirmed same results [34]

Conversely, Lawton $\mathrm{t}$ al, published new results of RTOG9413 with longer median follow up 6.6 years reported no difference in PFS nor OAS between WPRT and PORT [23].

In this study, reported no significant difference in PFS and OAS between WPRT and PORT, those results differs from early results of RTOG9413 as the later compared 4 arms, beside WPRT vs PORT, the effect of neoadjuvant and concurrent (NCHT) vs adjuvant hormonal (AHT) with WPRT and found better 4 years PFS with WPRT + NCHT than WPRT+AHT, PORT+NCHT and PORT+AHT $(60 \%$, $49 \%, 44 \%$, and $50 \%$ ) respectively, so no homogenecity in applying hormonal therapy. In the current study all patients received NCHT.

Second trial was GETUG-01 [22], which on the controversy of RTOG9413, reported with 42.1 months median follow up that no difference in 5 years PFS with rates of $66 \%$ and $65.3 \%$ for the pelvis + prostate versus prostate alone arms respectively $(\mathrm{P}=0.34)$. These result coincide with our results as regard effect of WPRT on PFS and OAS, but the current study used 2 years rate of PFS and OAS (78\% in WPRT vs $81 \%$ in PORT and $90 \%$ versus $92 \%$ respectively). This may be explained by the later study GETUG-01, studied low and high risk patients, in our study all patients were high risk, also considering shorter time of the study (3 years vs 6 years in later), and median follow up (26 months) than in GETUG-01 (42.1 months), beside lower number of patients in our study.

Many trials done some of which support improved survival of WP over PO [18, 31, 35-37], while others detected no benefit with elective nodal irradiation [21, 22, 38-40].

In 2015, Amini et al, [24], compared WPRT versus PORT in high risk node-negative prostate cancer used data-based registry, which concluded that no benefit of pelvic irradiation in these groups. Five years OAS was $81.6 \%$ and $83.9 \%$ in WPRT and PORT respectively $(\mathrm{P}=0.006)$. Also he predicted higher stage, increases age, higher PSA, and higher GS were associated with worse survival. Our study also detected same risk factors for survival, the similarity between our and Amini's attributed to same risk groups selection [25]. The 2 years OAS for WPRT vs PORT in Amini etal, approximating ours ( $94 \%$ and $93 \%$ respectively).

The difference between our results plus who registered no difference vs trials reported benefit of WPRT as RTOG 9413 and Pan et al $[16,31]$ may be explained to many factors as, the later studies used heterogenous group of risk factors as those included patients with intermediate risk of LNI.

In addition, dose of radiotherapy used total dose $>66 \mathrm{~Gy}$, 
same as GETUG-01, where prostate received $70 \mathrm{~Gy}$ and pelvis 46.8Gy, which was lower than used in RTOG9413 (50.46Gy), especially that Perez et al, [41] confirmed decrease in pelvic recurrence with $\geq 50 \mathrm{~Gy}$ to whole pelvis.

Beside dose of RTH was the extension also explain difference in result with RTOG9413, as in the later used higher border than others including ours. Roach $\mathrm{M}$, et al [15], investigated whether mini-pelvis $(\leq 10 \times 11 \mathrm{~cm})$ affect PFS comparable to WPRT, and reported that radiotherapy field size has impact on PFS with support to nodal irradiation in patients with LNI risk $>15 \%$. However, this not match the others reported on difference with using PO, WP, and partial pelvis [40].

In this study reported no grade 4 toxicity and late grade 3 gastrointestinal observed in 2 cases in patients received WPRT with significant difference $(\mathrm{P}=0.044)$, and grade 3 genitourinary in only one case in patients received PORT with no significance $(\mathrm{P}=0.096)$. This results resemble those observed in Aizer et al [18], as there increase in acute gastrointestinal toxicity in WPRT $(\mathrm{P}=0.048)$, but there were no difference in late nor genitourinary toxicity. Also it coincides with Roach et al, and Pommier et al [15, 22], as there increase in late gastrointestinal toxicity in WPRT with no difference in genitourinary.

\section{Conclusion}

The results of the current study didn't detect improvement of PFS nor OAS in patients received WPRT vs PORT, and these results agree with the trials observed same effect. However, recommend future studies with larger number, longer period of studies and follow up to confirm these results. More clinical trials with more selection of patients according to risk factors are considered to detect patients who benefit or not of pelvic irradiation. Also, variables dose escalation with advanced radiotherapy techniques should be performed. So, the routine use of WPRT is not supported.

\section{References}

[1] Amal S., Hussein M., Nabiel N., Hoda Baraka, and Hossam Kamel: Cancer incidence in Egypt: Results of the National population based cancer registery program. J Cancer Epidemiol. $2014: 437971$.

[2] Arfa M., Rabah D., Wahdan I. : Awareness of general public towards cancer prostate \& screening practice in Arabic communities: a comparative multi-center study. Asian Pac. J. Cancer Prev. 2012; 13:4321-4326.

[3] American Cancer Society, Prostate Cancer, 2015.

[4] Cooperberg M., Broering J., \& Carroll P.,: Time trends and local variation in primary treatment of localized prostate cancer. J. Clin. Oncol. 2010; 28:1117-1123 .

[5] Thompson I., Thrasher J., Aus G., Burnett A., Canby-Hagino E., Cookson M., et al.: Guideline for the management of clinically localized prostate cancer: J. Urol. 2007; 177: 21062131.
[6] Roach III M., Lu J., Pilepich M., Asbell S., Mohiuddin M., Terry R., et al: Four prognostic groups predict long-term survival from prostate cancer following radiotherapy alone on Radiation Therapy Oncology Group clinical trials. Int. J. Radiat. Oncol. Biol. Phys. 2000; 47: 609-615 .

[7] Roach III M., Weinberg V., Nash M., Sandler H., McLaughlin P., Kattan M.: Defining high risk prostate cancer with risk groups and nomograms: implications for designing clinical trials. J. Urol.2006; 176:16-20.

[8] Coen J., Zietman A., Thakral H., Shipley W.: Radical radiation for localized prostate cancer: local persistence of disease results in a late wave of metastases. Journal of Clinical Oncology, 2002; 20: 3199-3205.

[9] Zelefsky M., Reuter V., Fuks Z., Scardino P, Shippy A.: Influence of local tumor control on distant metastases and cancer related mortality after external beam radiotherapy for prostate cancer. Journal of Urology, 2008; 179:1368-1373.

[10] Pilepich M., Winter K., Lawton C., Krisch R., Wolkov H., Movsas B., et al: Androgen suppression adjuvant to definitive radiotherapy in prostate carcinoma--long-term results of phase III RTOG 85-31. Int. J. Radiat. Oncol. Biol. Phys. 2005; $61: 1285-1290$.

[11] Widmark A., Klepp O., Solberg A., Damber J, Angelsen A, Fransson $\mathrm{P}$, et al.: Endocrine treatment, with or without radiotherapy, in locally advanced prostate cancer [SPCG7/SFUO-3]: an open randomised phase III trial. The Lancet. 2009; 373: 301-308.

[12] Warde P., Mason M., Ding K., Kirkbride P., Brundage M., Cowan R., et al: Combined androgen deprivation therapy and radiation therapy for locally advanced prostate cancer: a randomised, phase 3 trial. The Lancet.2011; 378: 2104-2111.

[13] Mason M., Parulekar W., Sydes M., Brundage M., Kirkbride P., Gospodarowicz M., et al.: Final report of the intergroup randomized study of combined androgen-deprivation therapy plus radiotherapy versus androgen-deprivation therapy alone in locally advanced prostate cancer. Journal of Clinical Oncology. 2015; 33: 2143-2150.

[14] Roach III M., Marquez C., You H., Narayan P., Coleman L., Nseyo U., et al.: Predicting the risk of lymph node involvement using the pre-treatment prostate specific antigen and Gleason score in men with clinically localized prostate cancer. Int. J. Radiat. Oncol. Biol. Phys.1994; 28:33-37.

[15] Roach III M., DeSilvio M., Valicenti R., Grignon D., Asbell S., Lawton C., et al.: Whole-pelvis, "mini-pelvis," or prostateonly external beam radiotherapy after neoadjuvant and concurrent hormonal therapy in patients treated in the Radiation Therapy Oncology Group 9413 trial. Int. J. Radiat. Oncol. Biol. Phys. 2006; 66: 647-653.

[16] Roach M III., DeSilvio M., Lawton C., Uhl V., Machtay M., Seider M., et al: Phase III trial comparing whole-pelvic versus prostate-only radiotherapy and neoadjuvant versus adjuvant combined androgen suppression: Radiation Therapy Oncology Group 9413. J Clin Oncol.2003; 21:1904-1911.

[17] Roach III M., Hunt D., Lawton C., Hsu I., Lustig R., Seider M., et al.: R adiation Therapy Oncology Group [RTOG] 9413: a randomized trial comparing Whole Pelvic Radiation Therapy [WPRT] to Prostate only [PORT] and Neoadjuvant Hormonal Therapy [NHT] to Adjuvant Hormonal Therapy [AHT]. Int. J. Radiat. Oncol. Biol. Phys. 2013 ; 87:106-107. 
[18] Aizer A., Yu J., McKeon A., Decker R., Colberg J., Peschel R.: Whole pelvic radiotherapy versus prostate only radiotherapy in the management of locally advanced or aggressive prostate adenocarcinoma. Int J Radiat Oncol Biol Phys. 2009; 75:1344-1349.

[19] Cozzarini C., Noris Chiorda B., Sini C., Fiorino C., Briganti A., Montorsi F., et al. Hematologic toxicity in patients treated with post-prostatectomy whole-pelvis irradiation with different intensity modulated radiation therapy techniques is not negligible and is prolonged: Preliminary results of a longitudinal, observational study. Int J Radiat Oncol Biol Phys. 2016; 95: 690-695.

[20] Ennis R.: Uncertainties regarding pelvic radiotherapy for prostate cancer. J Clin Oncol .2004; 22:2254-2255.

[21] Vargas C., Galalae R., Demanes J., Harsolia A., Meldolesi E., Nürnberg N., et al: Lack of benefit of pelvic radiation in prostate cancer patients with a high risk of positive pelvic lymph nodes treated with high-dose radiation. Int J Radiat Oncol Biol Phys.2005; 63:1474-1482.

[22] Pommiere P., Chabaud S., Leon J., Richaud P., Lesaunier F., Le Prise E., et al.: Is there a role for pelvic irradiation in localized prostate adenocarcinoma? Preliminary results of GETUG-01. J Clin Oncol. 2007; 25:5366-5373.

[23] Lawton C., DeSilvio M., Roach III M., Uhl V, Kirsch R, Seider M., et al.: An update of the phase III trial comparing whole pelvic to prostate only radiotherapy and neoadjuvant to adjuvant total androgen suppression: updated analysis of RTOG 94-13, with emphasis on unexpected hormone/radiation interactions. Int. J. Radiat. Oncol. Biol. Phys. 2007; 69: 646-655.

[24] Amini A., Jones B., Yeh N., Rusthoven C., Armstrong H., Kavanagh B.: Survival Outcomes of Whole-Pelvic Versus Prostate-Only Radiation Therapy for High-Risk Prostate Cancer Patients With Use of the National Cancer Data Base. Int J Radiat Oncol Biol Phys.2015; 93: 1052-1063.

[25] Mohler J., Kantoff P., Armstrong A., Bahnson R., Cohen M., D'Amico A., et al.: Prostate cancer, version 2.2014," Journal of the National Comprehensive Cancer Network.2015; 12: 686-718.

[26] Albert J., Karen A., Roach III M., Howard I. . High-risk prostate cancer - classification and therapy. Nature Reviews Clinical Oncology. 2015; 11:308-323.

[27] Kuban D, Tucker S, Dong L, et al. Long-term results of the MD Anderson randomized dose-escalation trial for prostate cancer. Int J Radiat Oncol Biol Phys. 2008; 70:67-74.

[28] Zietman A., DeSilvio M., Slater J., Rossi C., Miller D., Adams J., et al. Comparison of conventional-dose vs highdose conformal radiation therapy in clinically localized adenocarcinoma of the prostate: A randomized controlled trial. JAMA. 2005; 294:1233-1239.

[29] Michalski J, Moughan J, Purdy J, Bosch W., Bahary J., Lau H., et al. A randomized trial of 79.2 Gy versus 70.2 Gy radiation therapy $[\mathrm{RT}]$ for localized prostate cancer. J Clin Oncol. 2015; 33 [suppl 7; abstr 4].
[30] Valicenti RK, Bae K, Michalski J, Sandler, H., Shipley, W., Lin, A., et al. Does hormone therapy reduce disease recurrence in prostate cancer patients receiving dose-escalated radiation therapy? An analysis of Radiation Therapy Oncology Group 94-06. Int J Radiat Oncol Biol Phys. 2011; 79: $1323-1329$.

[31] Pan C., Kim K., Taylor J., McLaughlin P., Sandler H.: Influence of 3D-CRT pelvic irradiation on outcome in prostate cancer treated with external beam radiotherapy. Int J Radiat Oncol Biol Phys.2002; 53:1139-1145.

[32] Asbell S, Krall J, Pilepich M, Baerwald H., Sause W., Hank G., et al: Elective pelvic irradiation in stage A2, B carcinoma of the prostate: Analysis of RTOG 77-06. Int J Radiat Oncol Biol Phys.1988; 15:1307-1316.

[33] Asbell S, Martz K, Shin K, Sause W., Doggett R., Perez C., et al: Impact of surgical staging in evaluating the radiotherapeutic outcome in RTOG \#77-06, a phase III study for T1BN0M0 [A2] and T2N0M0 [B] prostate carcinoma. Int J Radiat Oncol Biol Phys. 1998; 40:769-782.

[34] Lawton CA, DeSilvio M, Roach M, Uhl V, Kirsch R, Seider M., et al: An update of the phase III trial comparing whole-pelvic [WP] to prostate only [PO] radiotherapy and neoadjuvant to adjuvant total androgen suppression [TAS]: Updated analysis of RTOG 94-13. Int J Radiat Oncol Biol Phys.2005; 63:S19 [suppl].

[35] Seaward S., Weinberg V., Lewis P., Leigh B. , Phillips T., Roach III M.. Identification of a high-risk clinically localized prostate cancer subgroup receiving maximum benefit from whole-pelvic irradiation. Cancer J Sci Am. 1998; 4:370-377.

[36] Milecki P., Baczyk M., Skowronek J., Andrzej , Zbigniew K, Piotr 1. Benefit of whole pelvic radiotherapy combined with neoadjuvant androgen deprivation for the high-risk prostate cancer. J Biomed Biotechnol 2009; 625394.

[37] Lior Z, Mig-Hui C, Daniel, Sharon A., Michael J., Akash N., et al. Whole pelvis versus prostate-only radiotherapy with or without short course androgen deprivation therapy and mortality risk. Cl Genitour cancer. 2015; 13: 555-561.

[38] Vargas C, Demanes J, Boike T, Barnaba M., Skoolisariyaporn P., Schour L., et al. Matched-pair analysis of prostate cancer patients with a high risk of positive pelvic lymph nodes treated with and without pelvic RT and high-dose radiation using high dose rate brachytherapy. Am J Clin Oncol. 2006; 29:451-457.

[39] Soto D, Glaser S, Roberts R, Schipper M., McLaughlin P., Ray M., et al. Impact of common iliac nodal treatment on radiation outcomes in localized prostate cancer. Urology 2008; 71:313-317.

[40] Jacob R., Hanlon A., Horwitz E., Movsas B., Uzzo R., Pollack A. Role of prostate dose escalation in patients with greater than $15 \%$ risk of pelvic lymph node involvement. Int J Radiat Oncol Biol Phys. 2005; 61: 695-701.

[41] Perez C, Michalski J, Brown K, Ann L.: Nonrandomized evaluation of pelvic lymph node irradiation in localized carcinoma of the prostate. Int J Radiat Oncol Biol Phys.1996; 36:573-584. 